\title{
Biologic-free remission by orthopaedic surgery in non-responder to infliximab for rheumatoid arthritis
}

\author{
Katsuaki Kanbe*, Junji Chiba, Yasuo Inoue, Masashi Taguchi and Akiko Yabuki
}

\begin{abstract}
The aim of this study was to investigate remission and biologic-free remission after orthopaedic surgery and related clinical factors in non-responder to infliximab for rheumatoid arthritis (RA). We analyzed 74 patients who were treated with $3 \mathrm{mg} / \mathrm{kg}$ infliximab and methotrexate and underwent orthopaedic surgery after non-responder to infliximab with disease activity score (DAS) 28 (CRP) of $\geq 3$.2. The rates of remission and biologic-free remission at 52 weeks after orthopaedic surgery were investigated and the clinical factors related to remission and biologic-free remission were analyzed by logistic regression and receiver-operating characteristic analyses. The rates of total remission and biologic-free remission were 37/74 (50 \%) and 9/74 (12.2\%), respectively. Regarding orthopaedic surgery, the rates of remission and biologic-free remission were 25/38 (65.8\%) and 7/38 (18.4\%) for synovectomy, 7/20 (35\%) and $0 / 20(0 \%)$ for arthroplasty, and 5/16 (31.3\%) and 2/16 12.5) for others including spine surgery and foot surgery. DAS28(CRP) at baseline was significantly related to both remission and biologic-free remission. Prednisolone was negatively associated with remission, and DAS28(CRP) was related to biologic-free remission by logistic regression analyses. DAS28(CRP) below 3.7 was cutoff point for acquiring biologic-free remission of non-responder to infliximab after orthopaedic surgery. Therefore orthopaedic surgery may be effective to obtain remission or biologic-free remission in RA patients treated with biologics.
\end{abstract}

Keywords: Infliximab, Biologic-free, Remission, Orthopaedic surgery, Rheumatoid arthritis

\section{Background}

Anti-tumor necrosis factor (TNF)- $\alpha$ therapy such as infliximab for rheumatoid arthritis (RA) is used not only to inhibit inflammation, but also to suppress bone and joint destruction. It is reported that infliximab leads biologicfree remission in the long term for early RA patients with good responses (van der Kooij et al. 2009; Bejarano et al. 2010; Quinn et al. 2005; van der Bijl et al. 2007; van den Broek et al. 2011). However, it is difficult to induce biologic-free remission in non-responder to infliximab. No reports to date have described how orthopaedic surgery contributes to remission or biologic-free remission. AntiTNF- $\alpha$ therapy cannot improve the clinical outcomes in some patients with joint swelling and tenderness with

*Correspondence: kanbeor@dnh.twmu.ac.jp

Department of Orthopaedic Surgery, Tokyo Women's Medical University,

Medical Center East, 2-1-10 Nishiogu, Arakawa, Tokyo 116-8567, Japan bone destruction and synovium proliferation, and such patients are indicated to undergo orthopaedic surgery, such as total arthroplasty or arthroscopic synovectomy (Momohara et al. 2011; Kanbe and Inoue 2006). However, it remains unclear which orthopaedic surgeries are suitable for the induction of remission as well as biologicfree remission in infliximab treatment, and how clinical factors are related to these outcomes. In this study, we treated 74 patients by orthopaedic surgery among cases with non-responder to infliximab [disease activity score (DAS) 28 (CRP) of $\geq 3.2$. Retrospective and case studies were analyzed to detect specific factors related to remission and biologic-free remission after orthopaedic surgery under treatment with infliximab in RA. This is the first report related to bio-free remission by orthopaedic surgery for RA.

\section{Springer}

(c) 2015 Kanbe et al. This article is distributed under the terms of the Creative Commons Attribution 4.0 International License (http://creativecommons.org/licenses/by/4.0/), which permits unrestricted use, distribution, and reproduction in any medium, provided you give appropriate credit to the original author(s) and the source, provide a link to the Creative Commons license, and indicate if changes were made. 


\section{Methods}

\section{Patients and methods}

Seventy-four patients (9 males and 65 females) with a mean age of $60.4 \pm 1.05$ years, mean disease duration of $12.29 \pm 11.78$ years, mean disease activity score (DAS) 28 (CRP) of $4.32 \pm 0.71$, mean CRP of $2.67 \pm 3.22 \mathrm{mg} / \mathrm{dL}$, mean methotrexate (MTX) dose of $6.02 \pm 1.17 \mathrm{mg} /$ week, and mean prednisolone (PSL) dose of $3.68 \pm 2.29 \mathrm{mg} /$ day were treated by orthopaedic surgery in non-responder to $3 \mathrm{mg} / \mathrm{kg}$ infliximab for a mean period of $1.15 \pm 0.53$ years (Table 1 ). The 74 orthopaedic surgeries included 38 synovectomy procedures in 33 knees, three shoulders, one elbow, and one wrist, 20 arthroplasty procedures comprising 8 total knee arthroplasties (TKA), three total hip arthroplasties (THA), five total shoulder arthroplasties (TSA), three total elbow arthroplasties (TEA), and one total ankle arthroplasty (TAA), and 16 other procedures comprising six spine surgeries, eight foot surgeries, and two hand surgeries. The rehabilitation was also performed after all orthopaedic procedures. The treatment of infliximab was stopped around 4 weeks before surgery and restarted approximately around 4 weeks after surgery. MTX was stopped only one week of surgery, however PSL was continued. The infliximab treatment included a diagnosis of RA based on the American College of Rheumatology (ACR) criteria (Arnett et al. 1988), and categorization according to Steinbrocker et al. (Steinbrocker et al. 1949). The disease stages were stage II in 16 patients, stage III in 40 patients, and stage IV in 18 patients. The classes were class 2 in 20 patients, class 3 in 46 patients, and class 4 in 8 patients. At 52 weeks after surgery, the DAS28(CRP) was analyzed for the rates of remission, DAS28(CRP) of $\leq 2.6$, and biologic-free remission (Hirata et al. 2013; van der Heijde et al. 1990).

Table 1 Patients backgrounds at base line for orthopaedic surgery

\begin{tabular}{ll}
\hline $\mathrm{N}$ & 74 \\
Age (years) & $60.4 \pm 1.05$ \\
Female (\%) & $65 / 74(87.8 \%)$ \\
DD (years) & $12.29 \pm 11.78$ \\
DAS28(CRP) & $4.32 \pm 0.71$ \\
CRP (mg/dl) & $2.67 \pm 3.22$ \\
MTX (mg/week) & $6.02 \pm 1.17$ \\
PSL (mg/day) & $3.68 \pm 2.29$ \\
Stage/class & II; 16, III; 40, IV; $18 / 2 ; 20,3 ; 46,4 ; 8$ \\
Infliximab (years) & $1.15 \pm 0.53$ \\
Orthopaedic surgery & Synovectomy 38 \\
& Arthroplasty 20 \\
& Others 16 \\
\hline
\end{tabular}

$D D$ disease duration, DAS disease activity score, CRP c-reactive protein, $M T X$ methotrexate, $P S L$ predonisolone
Biologic-free remission was obtained after remission accomplished at 24 weeks after surgery. Logistic regression analyses were performed for age, disease duration, DAS28(CRP), dose of PSL, dose of MTX, stages and class at baseline. Receiver-operating characteristic (ROC) analyses were performed to acquire the cutoff points with sensitivity and specificity related to the significant clinical factors. Informed consent was obtained from all patients, and the study protocol was approved by the ethics committee of Tokyo Women's Medical University (approval number 1321).

\section{Statistical analysis}

The Wilcoxon signed-rank test was used to compare the DAS28(CRP) scores at baseline and 52 weeks after orthopaedic surgery. Logistic regression analyses related to remission and biologic-free remission were, respectively carried out at 52 weeks using StatFlex version 6.0 (Statflex, Tokyo, Japan). ROC curves were calculated to acquire the sensitivity and specificity with odds ratios of the clinical factors using the above software. Values of $p<0.05$ were considered significant.

\section{Results}

The remission rate of the total patients at 52 weeks was $37 / 74$ (50\%), including 25/38 (65.8\%) for synovectomy, $7 / 20$ (35\%) for arthroplasty, and 5/16 (31.3\%) for others (Table 2). The biologic-free remission rate was $9 / 74$ (12.2\%), including $7 / 38$ (18.4 \%) for synovectomy, 0/20 (0 \%) for arthroplasty, and 2/16 (12.5\%) for others (Table 2). The Boolean remission was 27/74 (36.5 \%) and bio-free Boolean remission was 8/74 (10.8\%) after surgery. The rates of remission and biologic-free remission continued, being 19/37 (51.4\%) and 7/9 (77.8\%) at 104 weeks after orthopaedic surgery, respectively. The logistic regression analyses showed that DAS28(CRP) at baseline $(p=0.0025)$ and PSL $(p=0.0348)$ were related to remission (Table 3 ). Therefore, low DAS28(CRP) at baseline and low dose of PSL were significantly correlated with remission. However, the logistic regression analyses showed that DAS28(CRP) at baseline $(p=0.0401)$ were related to biologic-free remission (Table 4 ). Therefore, low DAS28(CRP) at baseline was significantly correlated with biologic-free remission after orthopaedic surgery.

Table 2 Remission and bio-free rate after orthopaedic surgery

\begin{tabular}{lllll}
\hline & Total & $\begin{array}{l}\text { Synovec- } \\
\text { tomy }\end{array}$ & $\begin{array}{l}\text { Arthro- } \\
\text { plasty }\end{array}$ & Others \\
\hline $\begin{array}{l}\text { Remission } \\
\text { rate }\end{array}$ & $37 / 74(50 \%)$ & $\begin{array}{l}25 / 38 \\
(65.8 \%)\end{array}$ & $7 / 20(35 \%)$ & $5 / 16(31.3 \%)$ \\
$\begin{array}{c}\text { Bio-free rate } \\
\text { (12.2\%) }\end{array}$ & $9 / 7 / 38(18.4 \%)$ & $0 / 20(0 \%)$ & $2 / 16(12.5 \%)$ \\
\hline
\end{tabular}


Table 3 Clinical factors related to the remission

\begin{tabular}{llll}
\hline Factors & $\mathbf{P}$ & $\mathbf{O d d s}$ & $\mathbf{9 5} \% \mathbf{C l}$ \\
\hline Age & 0.5574 & 0.97981 & $0.91525-1.04892$ \\
DD & 0.7197 & 0.99877 & $0.99207-1.00551$ \\
DAS28 & 0.0025 & 0.03237 & $0.00351-0.29830$ \\
PSL & 0.0348 & 0.53672 & $0.30112-0.95665$ \\
MTX & 0.6036 & 1.26905 & $0.51632-3.11920$ \\
Stage & 0.6344 & 1.56574 & $0.24664-9.93964$ \\
Class & 0.1442 & 0.33875 & $0.07925-1.44801$
\end{tabular}

$D D$ disease duration, DAS disease activity score, $P S L$ predonisolone, $M T X$ methotrexate

Table 4 Clinical factors related to the biologic-free remission

\begin{tabular}{llll}
\hline Factors & $\mathbf{P}$ & Odds & $\mathbf{9 5} \% \mathbf{C l}$ \\
\hline Age & 0.0875 & 1.27742 & $0.96462-1.69165$ \\
DD & 0.3805 & 0.9947 & $0.98294-1.00659$ \\
DAS28 & 0.0401 & 0.00284 & $0.00001-0.76627$ \\
PSL & 0.3289 & 1.53217 & $0.65064-3.60805$ \\
MTX & 0.9742 & 0.98265 & $0.34078-2.83353$ \\
Stage & 0.8398 & 0.64611 & $0.00936-44.5802$ \\
Class & 0.9247 & 1.18464 & $0.03524-39.8251$ \\
\hline
\end{tabular}

$D D$ disease duration, DAS disease activity score, $P S L$ predonisolone, $M T X$ methotrexate

The DAS28(CRP) at baseline differed significantly, being $4.428 \pm 0.685$ in the no biologic-free remission group and $3.567 \pm 0.265$ in the biologic-free remission group $(p<0.0004)$ (Fig. 1). The ROC analyses showed that the cutoff point for DAS28(CRP) was 3.7, with sensitivity of 0.78 , specificity of 0.83 , and odds ratio of 17.2 (Fig. 2). Therefore, DAS28(CRP) below 3.7 was significantly correlated with obtaining biologic-free remission after orthopaedic surgery in treatment of non-responder to infliximab for RA (Fig. 2).

\section{Discussion}

Biologic-free treatment in RA was first reported in the TNF20 study (Bejarano et al. 2010; Quinn et al. 2005). Patients with early RA who had experienced symptoms for $<12$ months were treated with a combination of infliximab and MTX. Patients who initiated treatment with infliximab and MTX achieved higher American College of Rheumatology 50 and $70 \%$ improvement responses than patients who initiated therapy with MTX and placebo. At 1 year after stopping the induction therapy, the response was sustained in $70 \%$ of patients who received infliximab and MTX. In the Best study, it was described that infliximab had potential for biologic-free remission in the longterm results, with $56 \%$ discontinuation of infliximab at
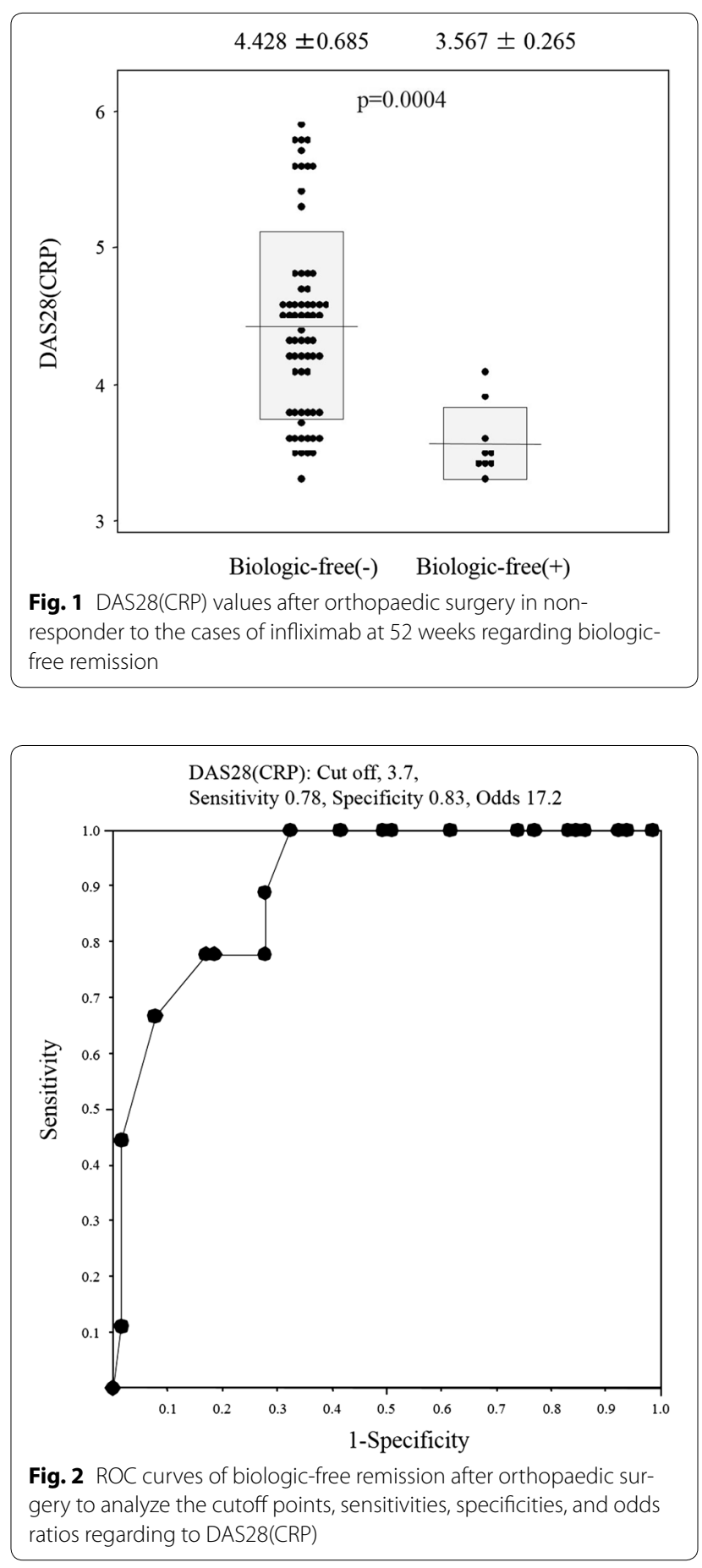

$\geq 6$ months and $52 \%$ at 7.2 years (van der Kooij et al. 2009; van der Bijl et al. 2007; van den Broek et al. 2011). Other biologics such as adalimumab were also reported for biologic-free remission, as $58 \%$ of patients achieved adalimumab-free remission at the primary end point of 6 months after discontinuation of adalimumab (Felson et al. 2011). However, there is no evidence for acquisition 
of remission or biologic-free remission of non-responder to infliximab in RA. We previously reported that synovectomy was effective for non-responder cases of infliximab to improve the DAS28 after surgery (Kanbe and Inoue 2006). Arthroplasty was also reported as a method for restoring biologic efficacy (Momohara et al. 2011). Although the mechanism for non-responder to infliximab is unknown, serum levels of IL- 6 were upregulated, even with the use of TNF- $\alpha$ blockers (Takeuchi et al. 2012). It was reported that TNF- $\alpha$ expression in the synovium was correlated with DAS28(CRP) by immunohistochemistry (Kanbe et al. 2013). Orthopaedic surgery may have a role in removing the synovium containing TNF- $\alpha$ and other cytokines, thereby reducing the inflammation to maintain biologic efficacy. This study showed $50 \%$ remission after orthopaedic surgery even under non-responder of infliximab and $12.2 \%$ biologic-free remission. In particular, synovectomy was more effective than other surgical treatments, meaning that direct removal of synovial tissue might be useful for infliximab toleration. The baseline DAS28(CRP) played a role in predicting the efficacy of orthopaedic surgery for remission as well as biologic-free remission, even for DAS28(CRP) of $\geq 3.2$. Thus, lower disease activity in non-responder to infliximab was suitable for application of surgery to acquire biologic-free remission. Furthermore, early timing of orthopaedic surgery after toleration of infliximab may be important to obtain a high rate of remission before increasing DAS28(CRP). The rates of remission and biologic-free remission continued at 51.4 and $77.8 \%$, respectively, at 104 weeks after orthopaedic surgery. Thus, biologic-free remission was stable for a relatively long period in this study. In the ROC analyses, we found that DAS28(CRP) below 3.7 showed high potential for obtaining biologic-free remission in non-responder to infliximab after orthopaedic surgery. This indicated that low disease activity may require restoration of joint functions by orthopaedic surgery before withdrawing biologics.

The limitations of this study are related to its retrospective nature, including the small number of patients $(n=74)$ and absence of a non-operative control group for comparison with cases of DAS28(CRP) of $\geq 3$.2. Future studies should consider the long-term results of biologicfree remission cases after orthopaedic surgery, and joint destruction by X-ray assessment should be evaluated.

\section{Conclusions}

Orthopaedic surgery was effective for non-responder to infliximab treated cases to obtain remission or biologicfree remission among RA patients with low disease activity.

\section{Authors' contributions}

KK participated in the design of the study and performed the statistical analysis. JC, YI, MT and AY conceived of the study and helped to draft the manuscript. All authors read and approved the final manuscript.

\section{Acknowledgements}

This study was supported in part by a Grant-in-Aid for Scientific Research (KAKENHI) (C) (24592284) from the Ministry of Education, Culture, Sports, Science and Technology and the Japan Society for the Promotion of Science.

\section{Competing interests}

The authors declare that they have no competing interests.

Received: 27 March 2015 Accepted: 5 October 2015

Published online: 13 October 2015

\section{References}

Arnett FC, Edworthy SM, Bloch DA, McShane DJ, Fries JF, Cooper NS, Healey LA, Kaplan SR, Liang MH, Luthra HS (1988) The American Rheumatism Association 1987 revised criteria for the classification of rheumatoid arthritis. Arthritis Rheum 31:315-324

Bejarano V, Conaghan PG, Quinn MA, Saleem B, Emery P (2010) Benefits 8 years after a remission induction regime with an infliximab and methotrexate combination in early rheumatoid arthritis. Rheumatology (Oxford) 49:1971-1974

Felson DT, Smolen JS, Wells G et al (2011) American College of Rheumatology/ European League Against Rheumatism provisional definition of remission in rheumatoid arthritis for clinical trials. Arthritis Rheum 63:573-586

Hirata S, Saito K, Kubo S, Fukuyo S, Mizuno Y, Iwata S, Nawata M, Sawamukai N, Nakano K, Yamaoka K, Tanaka Y (2013) Discontinuation of adalimumab after attaining disease activity score 28-erythrocyte sedimentation rate remission in patients with rheumatoid arthritis (HONOR study): an observational study. Arthritis Res Ther 15:R135

Kanbe K, Inoue K (2006) Efficacy of arthroscopic synovectomy for the effect attenuation cases of infliximab in rheumatoid arthritis. Clin Rheumatol 25:877-881

Kanbe K, Hara R, Chiba J, Inoue Y, Taguchi M, Tanaka Y (2013) Application of a new immunohistology scoring system (IH score): analysis of TNF- $\alpha$ in synovium related to disease activity score in infliximab-treated patients with rheumatoid arthritis. Mod Rheumatol 23:1053-1062

Momohara S, Inoue E, Ikari K, Yano K, Tokita A, Suzuki T, Sakuma Y, Hiroshima R, Kawakami K, Masuda I, Iwamoto T, Taniguchi A, Yamanaka H (2011) Efficacy of total joint arthroplasty in patients with established rheumatoid arthritis: improved longitudinal effects on disease activity but not on health-related quality of life. Mod Rheumatol 21:476-481

Quinn MA, Conaghan PG, O'Connor PJ, Karim Z, Greenstein A, Brown A, Brown C, Fraser A, Jarret S, Emery P (2005) Very early treatment with infliximab in addition to methotrexate in early, poor-prognosis rheumatoid arthritis reduces magnetic resonance imaging evidence of synovitis and damage, with sustained benefit after infliximab withdrawal: results from a twelvemonth randomized, double-blind, placebo-controlled trial. Arthritis Rheum 52:27-35

Steinbrocker O, Traeger CH, Battman RC (1949) Therapeutic criteria in rheumatoid arthritis. JAMA 140:659-662

Takeuchi T, Miyasaka N, Tatsuki Y, Yano T, Yoshinari T, Abe T, Koike T (2012) Inhibition of plasma IL-6 in addition to maintenance of an efficacious trough level of infliximab associated with clinical remission in patients with rheumatoid arthritis: analysis of the RISING Study. Ann Rheum Dis 71:1583-1585

van den Broek M, Klarenbeek NB, Dirven L, van Schaardenburg D, Hulsmans HM, Kerstens PJ, Huizinga TW, Dijkmans BA, Allaart CF (2011) Discontinuation of infliximab and potential predictors of persistent low disease activity in patients with early rheumatoid arthritis and disease activity score-steered therapy: subanalysis of the BeSt study. Ann Rheum Dis 70:1389-1394 
van der Bijl AE, Goekoop-Ruiterman YP, de Vries-Bouwstra JK, Ten Wolde S, Han KH, van Krugten MV, Allaart CF, Breedveld FC, Dijkmans BA (2007) Infliximab and methotrexate as induction therapy in patients with early rheumatoid arthritis. Arthritis Rheum 56:2129-2134

van der Heijde DM, van't Hof MA, van Riel PL et al (1990) Judging disease activity in clinical practice in rheumatoid arthritis: first step in the development of a disease activity score. Ann Rheum Dis 49:916-920 van der Kooij SM, le Cessie S, Goekoop-Ruiterman YP, de Vries-Bouwstra JK, van Zeben D, Kerstens PJ, Hazes JM, van Schaardenburg D, Breedveld FC, Dijkmans BA, Allaart CF (2009) Clinical and radiological efficacy of initial vs delayed treatment with infliximab plus methotrexate in patients with early rheumatoid arthritis. Ann Rheum Dis 68:1153-1158

\section{Submit your manuscript to a SpringerOpen ${ }^{\odot}$ journal and benefit from:}

- Convenient online submission

- Rigorous peer review

- Immediate publication on acceptance

- Open access: articles freely available online

- High visibility within the field

- Retaining the copyright to your article

Submit your next manuscript at $>$ springeropen.com 